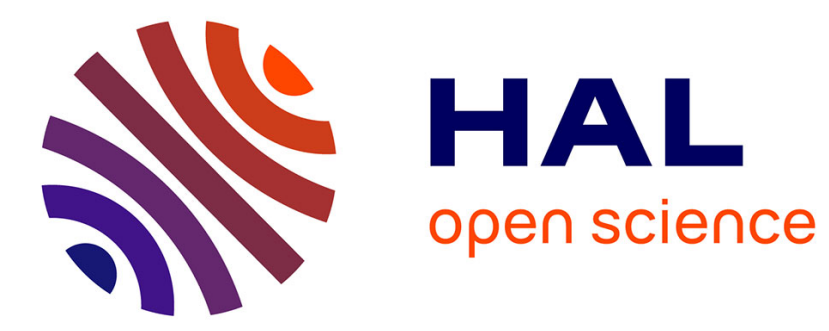

\title{
The design of an optimal area yield crop insurance contract
}

Olivier Mahul

\section{To cite this version:}

Olivier Mahul. The design of an optimal area yield crop insurance contract. 1er séminaire jeunes chercheurs, Dec 1997, Dourdon, France. 13 p. hal-01952129

\section{HAL Id: hal-01952129 \\ https://hal.science/hal-01952129}

Submitted on 7 Jun 2020

HAL is a multi-disciplinary open access archive for the deposit and dissemination of scientific research documents, whether they are published or not. The documents may come from teaching and research institutions in France or abroad, or from public or private research centers.
L'archive ouverte pluridisciplinaire HAL, est destinée au dépôt et à la diffusion de documents scientifiques de niveau recherche, publiés ou non, émanant des établissements d'enseignement et de recherche français ou étrangers, des laboratoires publics ou privés.

\section{(이) $\$$}

Distributed under a Creative Commons Attribution - NonCommercial - NoDerivatives| 4.0 
INSTITUT NATIONAL OE LA RECHERLHE AGHUIXunarisu Station d'Economie et Sociologie Rurales DOCUMENTATION 65, Rue de St Brieuc 35042 RENNES CEDEX Tél. : 99.28.54.08 et 09

The Design of Optimal Area Yield Crop Insurance Contract Mahul Olivier (INRA - Rennes) 


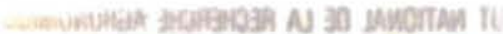

achuf gigutione is amsendo noing

ИOTTATИลMUวOC

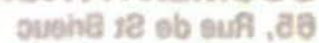

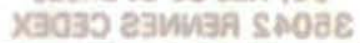

80 m 80.Aa.8s.ee : . . 


\title{
The Design of Optimal Area Yield Crop Insurance Contract
}

\author{
Olivier MAHUL ${ }^{*}$
}

\begin{abstract}
This paper focuses on the optimal design of crop insurance contract when both the indemnity and the premium are based on the aggregate yield of a surrounding geographical area. Full insurance under a trigger yield may be efficient for some amounts of damage even if the insurance company is riskaverse and the cost function is convex. When a positive linear relationship exists between the individual yield and the aggregate yield, the optimal crop insurance contract contains a disappearing deductible if the beta coefficient, which measures the sensitivity of the total risk to the systemic risk, is higher than unity and it contains coinsurance under a trigger yield otherwise. It may be a new tool for managing crop yield risks as European Union advocates the establishment of Community crop insurance market.
\end{abstract}

Keywords : crop insurance, market failure, systemic risk.

"Institut National de la Recherche Agronomique (INRA-ESR), 65 rue de Saint Brieuc 35042 Rennes cedex, France, e-mail : mahul@roazhon.inra.fr. 


\section{INTRODUCTION}

Agricultural production is typically a risky business. Yield uncertainty arising from climatic or epidemic fluctuations is one of the most important source in the variability of farmer's income. The agricultural economic literature tries to explain why private crop insurance markets fail without government subsidies. Recent articles focus attention on the specificity of agricultural risks and the limits of their insurability (Ahsan et al. 1982, Nelson and Loehman 1987, Chambers 1988, Quiggin 1994). A risk is said insurable if, given an economic environment, a mutually advantageous risk transfer can be exploited by the consumer and the supplier of insurance. The standard theory of risk sharing concludes that, in the presence of a single source of risk, socially efficient insurance provides coinsurance or full insurance above a straight deductible, depending on the insurer's risk aversion and the transaction cost function (Arrow 1971, Raviv 1979). These results are not altered when an irdependent zero-mean background risk is introduced (Gollier 1996).

In this paper, the individual risk is decomposed into a systemic component and a nonsystemic residual component. Systemic risk affects simultaneously all producers in a given area and it is beyond their control whereas nonsystemic risk may be altered by their actions. We define the optimal insurance contract of systemic risk when the nonsystemic risk is assumed uninsurable. The efficient design depends on the relationship between these two components of risk. It may exhibit disappearing deductible even if the insurer is risk-averse and if the transaction cost function is convex.

This model is useful for characterizing the optimal design of an area yield crop insurance contract. This contract offers protection against regional yield shortfalls. In this alternative crop insurance scheme, both the indemnity and the premium are based on the aggregate yield of a surrounding geographical area. It differs from standard insurance contract which is based on individual variables. This area yield insurance contract allows to significantly reduce moral hazard and adverse selection which are possible causes for the nonexistence of private all-risk crop insurance (Knight and Coble 1997).

We derive in the next section the optimal design of aggregate yield insurance contract. The third section is devoted to the area yield crop insurance contract. In the fourth section, we describe the disaster programs provided to French farmers and we show how this alternative insurance contract may play a key role in the development of European private crop insurance market.

\section{OPTIMAL DESIGN OF AGGREGATE YIELD INSURANCE CONTRACT}

A risk-averse producer $i$ is endowed with initial wealth $\pi_{0}$ and a random yield $\tilde{y}_{i}$ due to the uncertain effects of weather and other natural phenomena. Output price is assumed certain and it is normalized to unity. The producer faces only production risk. Because we assume there is no moral hazard, the level of input to production is not taken into account. The producer has the opportunity to purchase insurance. Both the indemnity and the premium are not based on the individual yield but rather on the aggregate yield 
$\tilde{y}$ of a surrounding area. We assume the existence of a long-run stable relationship between farm yields and aggregate yields characterized by :

$$
\widetilde{y}_{i}=g_{i}(\tilde{y})+\widetilde{\varepsilon}_{i}
$$

where $\widetilde{\varepsilon}_{i}$ and $\widetilde{y}$ are assumed independent and $E \widetilde{\varepsilon}_{i}=0$. The aggregate yield is distributed according to the cumulative distribution function $\Phi($.$) , with support$ $\left[0, y_{\max }\right]$ where $y_{\max }$ is the maximum aggregate yield which can be obtained. The expected aggregate yield is denoted $\mu \equiv E \tilde{y}$ and the expected individual yield is $\mu_{i} \equiv E \widetilde{y}_{i}$. Equation (1) decomposes individual yield into a systemic component $g_{i}(\tilde{y})$ that is perfectly correlated with the aggregate yield and a nonsystemic component $\widetilde{\varepsilon}_{i}$ that is uncorrelated with the aggregate yield. The systemic risk is mainly attributable to natural disasters which are beyond the producers' control. On the contrary, producers can partially control the nonsystemic risk which is mainly attributable to individual production practices.

Following Raviv (1979), the insurance contract is described by a couple $(I(), P$. where $I$ is the indemnity schedule and $P$ the premium. In other words, $I(y)$ is the indemnity received by the producer if the insurance company observes aggregate yield $y$. A feasible coverage function satisfies :

$$
I(y) \geq 0 \text { for all } y
$$

This means that an insurance reimbursement is necessarily nonnegative but this function may higher than the shortfall $\left(y_{\max }-y\right)$ where $y_{\max }$ is the maximum area yield which can be reached. This upper bound is often required in order to guard against moral hazard. It is not necessary in our model because the aggregate yield is not affected by the individual behaviors ${ }^{1}$. We also assume that the insured producer doesn't receive any indemnity when the aggregate yield is maximum : $I\left(y_{\max }\right)=0$.

The producer maximizes the expected utility of his final wealth $\pi$. His increasing and concave utility function is denoted $u($.$) , with u^{\prime}(\pi)>0$ and $u^{\prime \prime}(\pi)<0$ for all $\pi$. If the producer purchases this insurance policy, then his expected utility of wealth is

$$
\operatorname{Eu}\left(\pi_{0}+\tilde{y}_{i}+I(\tilde{y})-P\right)=\operatorname{Eu}\left(\pi_{0}+g_{i}(\tilde{y})+I(\tilde{y})-P\right)
$$

where $\hat{u}($.$) is the indirect utility function defined by$

$$
\hat{\imath}(\pi)=E u(\pi+\widetilde{\varepsilon}) \text { for all } \pi
$$

\footnotetext{
The aggregate yield is based on the individual yields of insured and uninsured producers. The area is assumed sufficiently large so that nobody is able to influence it.
} 
This indirect utility function inherits properties of the original utility function : it is increasing and concave (Kihlstrom et al. 1981). The producer purchases the insurance contract $(I(), P$.$) if his expected utility level is greater with this policy than without it :$

$$
E \hat{u}\left(\pi_{0}+g_{i}(\tilde{y})+I(\tilde{y})-P\right) \geq E \hat{u}\left(\pi_{0}+g_{i}(\tilde{y})\right)
$$

The insurance company maximizes the expected value of his utility function $v($.) which is increasing and concave, $v^{\prime}(w)>0$ and $v^{\prime \prime}(w) \leq 0$ for all $w$. The insurer faces transaction costs which correspond to general administrative costs, the cost of capital, the cost of marketing, the cost of claim-judgment and court costs. The increasing and convex function $c(I)$ represents these costs when insurance payment is $I$. They are divided into fixed and variable components :

$$
c(0)=c_{0} \geq 0, c^{\prime}(I) \geq 0 \text { and } c^{\prime \prime}(I) \geq 0 \text { for all } I
$$

If $w_{0}$ denotes his initial wealth, the insurer offers the insurance contract $(I(), P)$ if and only if

$$
E v\left[w_{0}+P-I(\tilde{y})-c(I(\tilde{y}))\right] \geq v\left(w_{0}\right)
$$

Conditions (5) and (7) define the set of contracts acceptable by both parties. We will assume that this set is not empty, so the systemic risk is insurable.

The Pareto optimal insurance design is the couple $(I(), P$.$) that maximizes the$ insured producer's expected utility of final wealth under the above-mentioned constraints

$$
\left\{\begin{array}{l}
\underset{P, I()}{\operatorname{Max}} \int_{0}^{y_{\max }} \hat{u}\left(\pi_{0}+g_{i}(y)+I(y)-P\right) d \Phi(y) \\
s l c \\
I(y) \geq 0 \text { for all } y \geq 0 \\
\int_{0}^{y_{\max }} v\left[w_{0}+P-I(y)-c(I(y))\right] d \Phi(y) \geq v\left(w_{0}\right)
\end{array}\right.
$$

The maximization problem (8) is a calculus variation problem which can be solved in two steps. The premium is first assumed fixed and the optimal insurance design is defined. Then the optimal insurance premium is chosen. Following Raviv (1979) and Kamien and Schwartz (I981), we obtain the first proposition. 


\section{Proposition 1}

The optimal crop insurance indemnity $I^{*}($ ) of aggregate yield which is solution of the maximization problem (8) when the premium is fixed is

$$
\begin{aligned}
& I^{*}(y)=\left\{\begin{array}{ll}
0 & \text { if } y \geq y_{i}^{*} \\
I^{*}(y)>0 & \text { if } y<y_{i}^{*}
\end{array} \quad \text { if } g_{i}^{\prime}(y)>0 \quad \forall y \in\left[0, y_{\max }\right],\right. \\
& I^{*}(y)=\left\{\begin{array}{lll}
0 & \text { if } & y \leq y_{i}^{* *} \\
I^{*}(y)>0 & \text { if } & y>y_{i}^{* *}
\end{array} \quad \text { if } g_{i}^{\prime}(y)<0 \quad \forall y \in\left[0, y_{\max }\right]\right. \\
& I^{*}(y)=0 \quad \forall y \geq 0 \quad \text { if } g_{i}^{\prime}(y)=0 \quad \forall y \in\left[0, y_{\max }\right]
\end{aligned}
$$

When $I^{*}(y)>0$, the optimal indemnity function satisfies

$$
I^{* \prime}(y)=-g_{i}^{\prime}(y) \frac{A_{\hat{u}}(\pi)}{A_{\hat{u}}(\pi)+\frac{c^{\prime \prime}}{1+c^{\prime}}+\left(1+c^{\prime}\right) A_{v}(w)} \quad \text { for all } y: I(y)>0
$$

with $w=w_{0}+P-I(y)-c(I(y)), \pi=\pi_{0}+g_{1}(y)+I(y)-P$, and $A_{\hat{u}}($.$) and A_{v}($.$) are$ respectively the index of absolute risk aversion associated with the insured producer's indirect utility function and the insurer's utility function.

Proof

Constraint (7) is binding at the optimum. The Hamiltonian of problem (8) is given by

$$
H=\left\{\hat{u}\left(\pi_{0}+g_{i}(y)+I(y)-P\right)+\zeta v\left[w_{0}+P-I(y)-c(I(y))\right]\right\} \varphi(y)
$$

where $\varphi($.$) is the density function of the aggregate yields, I(y)$ is the control variable and $\zeta$ is the multiplier function. It is invariant with respect to $y$ because the state variable doesn't appear in the Hamiltonian. The first order necessary conditions are

$$
\left\{\begin{array}{l}
I^{*}(y)=0 \Leftrightarrow J(y) \equiv \hat{u}^{\prime}\left(\pi_{0}+g_{i}(y)-P\right)-\zeta\left[1+c^{\prime}(0)\right] v^{\prime}\left(w_{0}+P-c_{0}\right) \leq 0 \\
I^{*}(y)>0 \Leftrightarrow \hat{u}^{\prime}(\pi)-\zeta\left[1+c^{\prime}\left(I^{*}(y)\right)\right] v^{\prime}\left(w^{\prime}\right)=0
\end{array}\right.
$$

We have

$$
\frac{d J}{d y}=g_{i}^{\prime}(y) \hat{u}^{\prime \prime}\left(\pi_{0}+g_{i}(y)-P\right)
$$

Since the insured producer is risk-averse, the function $J$ is decreasing (resp. increasing) if and only if $g_{i}^{\prime}($.$) is increasing (resp. decreasing). Consequently if g_{i}^{\prime}(y)>0$ for all $y \in\left[0, y_{\max }\right]$ there exists a unique $y_{i}^{*} \in\left[0, y_{\max }\right]$ such that $J(y) \cdot\left(y_{i}^{*}-y\right) \geq 0$ for all $y$, and if $g_{i}^{\prime}(y)<0$ for all $y \in\left[0, y_{\max }\right]$ there exists a unique $y_{i}^{* *} \in\left[0, y_{\max }\right]$ such that 
$J(y) \cdot\left(y_{i}^{* *}-y\right) \leq 0$ for all $y$. When $g_{i}(y)=0$ for all $y \in\left[0, y_{\max }\right]$, the individual yield doesn't depend on the aggregate yield. Therefore the producer doesn't buy the insurance contract. From this we deduce optimal insurance contracts given by expressions ( 9 ), (10) and (11). The differentiation with respect to $y$ of the above equality gives equation (12). Proposition 1 is demonstrated.

When the indemnity function is based on the individual yield, it is well known that the optimal insurance contract contains a critical yield above which there is no indemnity payment (Chambers 1989). When the transformation function $g_{i}($.$) is strictly increasing$ with respect to the aggregate yield, the optimal insurance design is such that an indemnity is paid if the aggregate yield falls below the critical yield level $y_{i}^{*}$. On the contrary, when the transformation function $g_{i}($.$) is strictly decreasing with respect to$ the aggregate yield, an indemnity is paid if the aggregate yield is higher than a critical yield level $y_{i}^{* *}$. This design is not standard and it is due to the negative relationship between the individual yield and the aggregate yield. However, this insurance scheme may be rather uncommon as we will see in the next section. We focus our attention on the first case. When the aggregate yield $y$ falls below the critical level $y_{i}^{*}$, the insurance contract provides full insurance under the trigger yield if $I^{\prime *}(y)=-1$, coinsurance if $I^{\prime *}(y)>-1$ and a disappearing deductible if $I^{\prime *}(y)<-1$. In this last case, the indemnity increases more than the decrease of the aggregate yield. It's worth noting that even if the insurer is risk-averse and the cost function is convex, the optimal insurance contract may contain full insurance under the critical yield for some amounts of damage if the first derivative of the transformation function $g_{i}$ is large enough and at least greater than one. When $g_{i}^{\prime}(y)<1$, coinsurance under the critical yield is always the optimal design.

When the insurance company is risk-neutral and the cost function is linear, equation (12) becomes :

$$
I^{* \prime}(y)=-g_{i}^{\prime}(y)
$$

For $y<y_{i}^{*}$, the insurance contract provides a disappearing deductible if and only if $g_{i}^{\prime}(y)>1$.

With terminal conditions $I^{*}\left(y_{i}^{*}\right)=0$ and $I^{*}\left(y_{i}^{* *}\right)=0$, the first proposition becomes:

\section{Corollary 1}

If the insurer is risk-neutral and the cost function is linear, the optimal insurance contract verifies
(i) $I^{*}(y)=\max \left[g_{i}\left(y_{i}^{*}\right)-g_{i}(y), 0\right]$
if $g_{i}^{\prime}(y)>0 \quad \forall y \in\left[0, y_{\max }\right]$;
(ii) $I^{*}(y)=\max \left[g_{i}\left(y_{i}^{* *}\right)-g_{i}(y), 0\right]$
if $g_{i}^{\prime}(y)<0 \quad \forall y \in\left[0, y_{\max }\right]$. 
The critical yield depends on producer's risk aversion and crop insurance premium. Following Raviv 1979), one can easily verify that the producer is therefore fully insured against the systemic risk, $y_{i}^{*}=y_{\max }$ or $y_{i}^{* *}=0$, if and only if the insurer's marginal cost function equals zero.

\section{AREA YIELD CROP INSURANCE CONTRACT}

Crop insurance program is an element of governmental policies aimed at solving problems about low and unstable farm incomes. Before 1980, the U.S. Department of Agriculture offers direct disaster assistance to farmers. When Congress enacted the Federal Crop Insurance Act of 1980 to replace disaster insurance, policy makers envisioned a crop insurance program that would operate on an actuarially sound basis with limited financial assistance. The Federal Crop Insurance Corporation (FCIC) was given authority to expand coverage to insure all crops in counties. Private insurers were largely responsible for marketing crop insurance and FCIC offers reinsurance to insurers. They were allowed to have a commission payment. Premiums were subsidized up to $30 \%$. Another important change was a move toward more individualized coverage. Despite these changes, participation rate remains low, even if it increased from $10 \%$ in 1980 to $38 \%$ in 1994 (Gardner I994). Actuarial performance of revised multiple peril crop insurance program was disappointing : the aggregate 1981-1994 loss ratio (indemnities/premiums) was 1.41 and during this period indemnities exceed premiums by $\$ 3.3$ billion (Knight and Coble 1997).

The agricultural economists examined explanations for the failure of private all-risk crop insurance markets. They try to explain why private sector is unable to provide affordable crop insurance services without large government subsidies. Therefore they wonder about the limits of insurability for agricultural risks. Recent research has focused on asymmetric information problems : moral hazard and adverse selection. Ex ante moral hazard occurs when insured producers alter their production practices in a manner that increases their chances of collecting indemnities (Chambers 1989). This asymmetric information was limited by requiring a deductible of at least $25 \%$ of the producer's expected yield. Adverse selection raises also serious problems. It arises because producers are better informed about their distribution of their own yields and thus are better able to assess the actuarial fairness of their premiums than the insurer (Seeks and Reed 1986). These asymmetries information problems can be partly resolved when the insurance company spends time and money collecting individual information and checking individual production histories. These administrative costs must be included in the premium and contribute to make the risk uninsurable or they are borne by the government crop insurance program.

Low participation and poor actuarial experience induced the FCIC to test new insurance designs. One of these pilot program is a national area yield crop insurance program. Area yield coverage has been offered for some crops in some counties since 1993. In this alternative crop insurance scheme, both indemnities and premiums are based not on a producer's individual yield but rather on the aggregate yield of a surrounding geographical area (Miranda 1991). Consequently, every insured producer in 
a given area receives an indemnity per insured acre, when the aggregate yield is lower than the critical yield, which is independent of his own crop yield.

Because this insurance scheme doesn't take into account the individual yield, except through the aggregate yield, asymmetric information problems are significantly reduced. Adverse selection is reduces because distribution of the area yield are generally available and more precise than the individual one. Ex ante moral hazard is reduced because production practices cannot alter the area yield. All these advantages contribute to reduce the administrative costs and therefore the premium rate.

Another insurability problem which is endemic to crop insurance was recently raised : the high degree of correlation among farm-level crop losses (Quiggin 1994, Miranda and Glauber 1997). Unlike other type of property insurance, crop losses are often due to natural disasters such as drought, flood or epidemic diseases which affect simultaneously a large number of farms. The systemic risk cannot be eliminated by using the mutuality principle. Shareholders of insurance company are not able to diversify this risk and, therefore, they ask for a risk premium which increases the premium rate paid by the insured producers. It can stymie the emergence of a crop insurance market. Since 1995, the Chicago Board of Trade (CBOT) has launched Crop Yield Insurance futures and options contracts. The first one was Iowa Corn Yield Insurance Futures and options and other contracts would follow. These contracts were meant to offer insurers an alternative to reinsurance.

Following Miranda (1991), the producer operates in an area where the average yield across farms is $\tilde{y}$. The producer's individual yield $\tilde{y}_{i}$ is projected onto the area yield and thus the following identity is obtained :

$$
\tilde{y}_{i}-\mu_{i}=\beta_{i}(\tilde{y}-\mu)+\tilde{\varepsilon}_{i}
$$

where

$$
\beta_{i}=\frac{\operatorname{cov}\left(\tilde{y}_{i}, \tilde{y}\right)}{\operatorname{var}(\tilde{y})} \text { and } \operatorname{cov}\left(\tilde{y}, \tilde{\varepsilon}_{i}\right)=0
$$

We assume that the nonsystemic component $\widetilde{\varepsilon}_{i}$ and the area yield $\tilde{y}$ are independent. The individual coefficient $\beta_{i}$, called beta coefficient, measures the sensitivity of the individual yield to the systematic factors that affect the area yield. Given equation (1), the above identity can be rewritten as

$$
\widetilde{y}_{i}=g_{i}(\tilde{y})+\widetilde{\varepsilon}_{i} \text { where } g_{i}(y)=\mu_{i}+\beta_{i}(y-\mu)
$$

From Proposition 1, the optimal insurance contract contains a deductible if the beta coefficient is positive and an upper limit if the beta coefficient is negative. When the insurer is risk-neutral and the cost function is linear, we obtain the following corollary. 


\section{Corollary 2}

Suppose that there exists a significant linear relationship between farm yields and area yields, the insurer is risk-neutral and the cost function is linear. The optimal crop insurance contract verifies :
(i) $I^{*}(y)=\beta_{i} \max \left[y_{i}^{*}-y, 0\right] \quad$ if $\beta_{i}>0$;
(ii) $I^{*}(y)=\beta_{i} \min \left[y_{i}^{* *}-y, 0\right] \quad$ if $\beta_{i}<0$.

The producer's beta coefficient plays a key role in the design of the optimal crop insurance contract. First, its positive or negative sign entails that an indemnity is paid when the area yield is under or above a critical yield. Negative beta coefficients are actually uncommon. Second, the fact that its absolute value is lower or greater than one implies that the optimal contract contains a coinsurance or a disappearing deductible. This optimal design is graphically represented with $0<\beta_{i}<\beta_{i}^{\prime}=1<\beta_{i}^{\prime \prime}$. If the beta coefficient is great enough, we can obtain $\beta_{i}^{\prime \prime \prime} y_{i}^{*}>y_{\max }$ : the insured producer is wealthier when a bad crop occurs than when the area yield is maximum.

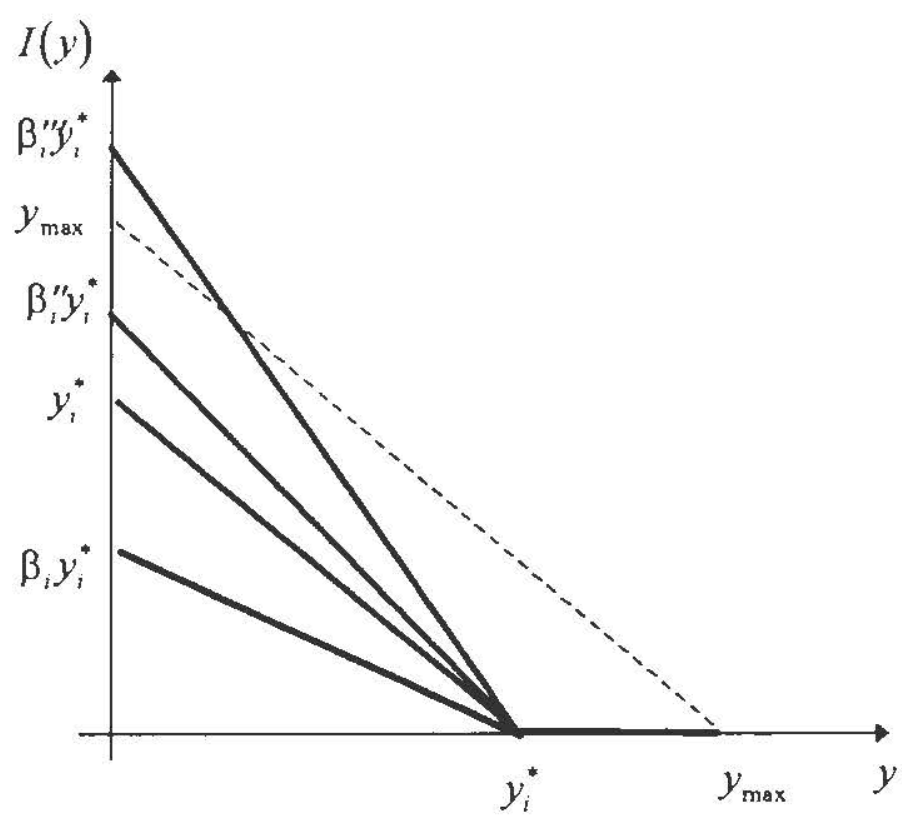

Figure 1. Optimal area yield crop insurance contract for $\beta_{1}>0$.

When the beta coefficient is positive, the area yield contract is like a put option : it provides a hedge for low area yields and thus low individual yields. When the beta coefficient is negative, this insurance contracts acts as a call option : an indemnity is paid when the area yield is higher than a critical level because of the negative correlation between the individual yield and the area yield. The FCIC offers the following pilot area yield contract :

$$
I^{C}(y)=\max \left[\phi_{i}\left(\alpha_{i} \mu-y\right), 0\right]
$$


and each farmer can choose the critical yield $y_{i}^{*}=\alpha_{i}^{*} \mu$ and the coverage level $\phi_{i}$. From Corollary 2 , the producer will choose his optimal coverage level such that it is equal to his beta coefficient, $\phi_{i}^{*}=\beta_{i}$. This insurance contract doesn't allow producers with negative beta to hedge against their individual low yield but empirical estimations show that this set of producers is very marginal (Miranda 1991, Carriker et al. 1991, Smith et al. 1994).

The linearity assumption of individual yields and area yields is the key to the successful implementation of the above insurance program. When a strictly monotonous relationship exists, our previous results allow to establish the optimal area yield crop insurance contract. Nevertheless its implementation may be rather difficult as it is shown in corollary 1 .

\section{TOWARD A FRENCH CROP INSURANCE MARKET}

French farmers are protected against natural disaster through three disaster assistance programs : the "Fonds National de Garantie contre les Calamités Agricoles" (FNGCA), the Catastrophe Insurance System and a crop insurance market.

The French crop insurance market is considered as undeveloped. It only provides a crop-hail insurance for most of crops, a guarantee against the effects of storm for some crops and a guarantee against the effects of frost for vine crop in some regions. The crop-hail insurance is widely underwritten in France. The participation rate is $60 \%$ and the amount of total premiums represents FF1.5 billion. The crop-hail insurance is subsidized by the Government but this subsidization decreased from FF120 million in 1990 to FF 15 millions in 1994 (Chapuis 1994). French insurance companies refuse to cover damage caused by other agricultural calamities.

French farmers are protected against these uninsurable risks through the special system FNGCA. Legislation defines a natural disaster as an event resulting from the abnormal intensity of a natural agent. In practice, this is flooding, landslide, drought, frost and storm, namely all natural risks which are not insurable. The disaster payments depend on the financial resources which are available. These resources come from additional premium which is calculated on the basis of a single rate set by decree for each category of policy. It applies to all premiums relating to damage contracts. It doesn't depend on the individual risk. The amount of this additional premium represent $60 \%$ of the resources. The French government provides an additional subsidy which is equal to FF550 million in 1997. Since the new compensation system for natural disasters instituted in 1982 (see after) the FNGCA provides compensations for damage caused to non-stored harvest, livestock outside buildings, cultivation and soils. But these compensations are mainly provided to non-stored harvest. The compensation system can be divided into three stages. First the event must be declared as a natural disaster by inter-ministerial decree if the uninsurable damage are considered sufficiently large. Farmers have to assess their losses during a second stage. In the last stage, a national committee establishes compensation rates. These three stages last usually one year. Losses caused by natural disasters are allowed to be compensated if they are larger than $27 \%$ of the farmer's final product and $14 \%$ of his total production. The compensation 
rate is equal to $28 \%$ if a guarantee damage caused by fire was underwritten and this rate is of $35 \%$ if a guarantee damage caused by hail was purchased. It's worth noting that no compensation is provided if none of these guarantees is underwritten. This system aims at inducing farmers to underwrite insurance contracts against natural damage.

Other natural disasters affecting farmers are covered by the Catastrophe Insurance System. This compensation system for natural disasters was instituted in 1982 . Insurance contracts guaranteeing fire and other damage to property located in France, damage to motor vehicles and losses business profits, are considered also guaranteeing the policy holder against direct material damage and losses of profits caused by a natural disaster. A state of natural disaster is declared by ministerial decree. This guarantee is financed by an additional premium, calculated on the basis of a single set by decree for each line of business. The system is balanced by the Central Re-insurance Company which intervenes under Government guarantee (Magnan 1995). Contrary to the FNGCA, this compensation system is managed by private insurance companies which can be reinsured at the Central Re-insurance Company. This public establishment is allowed to underwrite these risks with a guarantee from the State.

These two complementary compensation systems are based upon two levels of risk pooling. The first includes producers who have underwritten an insurance contract against property damage because this insurance is not compulsory. Additional premiums are the same for all the insured agents, whatever their individual risk. The second level includes the whole society through subsidies provided by the government to the FNGCA and the re-insurance system provided by the Central Re-insurance Company to insurance companies operating in France. Therefore the notion of solidarity prevails.

The FNGCA provides a disaster assistance to farmers facing uninsurable losses. But it is more and more criticized because it is not adapted any longer to the farmer's management of natural risks. The compensation system is slow, the subsidies are uncertain and low. Farmers need new tools for managing crop yield risks. Given the limits of the current compensation system, the European Union suggested in 1993 the creation of an unified compensation system for agricultural calamities and the establishment of an European private crop insurance market which would be capable of offering farmers crop insurance contracts. This insurance program would be managed by private insurance companies and the participation would be free. The governments would induce the farmers to purchase these insurance contracts through premium subsidy. This insurance program looks like the U.S. crop insurance program. Nevertheless it would be crucial to avoid major difficulties the FCIC is still confronted. Asymmetric information problems seem to be the main limits for the crop insurability.

Area yield crop insurance program offers a new insurance design. It allows to significantly reduce moral hazard, adverse selection and administrative costs because both indemnity and premium are based on the aggregate yield of a surrounding geographical area. This insurance design is all the more efficient as the individual yield risk and the aggregate risk are highly correlated. It provides a hedge for the systemic risk which affects simultaneously a large number of farmers and generates the largest losses. The farmers still bear the nonsystemic risk which is attributable to individual production practices. One of the aims of farm policies should be the reduction of the systemic risk, not the total risk. This crop insurance program allows to reach this goal 
with limited government financial assistance. It may allow to create an insurance program that would replace disasters relief measures while operating on an actuarially sound basis. Other proposals based on variables exogenous to the individual farm have been made, such as observed climatic experiences. Rainfall insurance allows the farmers to receive a payout whenever rainfall in their area falls below a specified level. The optimal form of such an insurance contract has been recently studied (Mahul 1997). These alternatives insurance schemes offer hedging opportunities which may help the development of a private crop insurance market.

\section{CONCLUSION}

This article is a first step in a research project on the analysis of the feasibility of a private crop insurance market in France. Such an insurance market would be able to provide farmers new tools for managing crop yield risks with limited government intervention. The existing special system guaranteeing agricultural calamities is less and less adapted to the french farmers' needs because the compensation system lasts one year, the subsidies are uncertain and imperfect.

Development in economic theory focused attention on several types of market failure as possible causes for the nonexistence of private all-risk crop insurance : the existence of moral hazard and adverse selection problems and the absence of pooling. Area yield crop insurance contract may essentially eliminate asymmetries of information which act as barriers for the insurability of risks. They provide the farmers a hedge for the nondiversifiable risk. In this paper, the optimal design of this area crop insurance policy is derived. When the relationship is linear, the beta coefficient play a key role. The optimal contract provides disappearing deductible if this coefficient is greater than one and coinsurance under the critical yield otherwise. Under standard assumptions, the optimal form of this insurance contract is straightforward and therefore its implementation should be feasible. It may have a relevant role in the development of an European private crop insurance market. Another alternative insurance program could consist in basing in basing the indemnity schedule upon weather variables such as rainfall (Mahul 1997).

Nevertheless the international insurance and reinsurance industry may be unable to pool this nondiversifiable risk. This generates additional cost of capital which are borne by policyholders through an increase of the crop insurance premium rate. Capital markets provide new opportunities for crop loss risks by creating new hedging tools based on regional yields. They may also consider the creation of assets based on observed climatic experience. 


\section{REFERENCES}

Arrow, K. J. 1971, Essays in the Theory of Risk Bearing, Chicago : Markham.

Ahsan, S.M., A. Ali and N. Kurian, 1982, Toward a Theory of Agricultural Insurance, American Journal of Agricultural Economics, 64: 520-529.

Carriker, G.L., J.R. Willians, G.A. Barnaby and J.R. Black, 1991, Yield and Income Risk Reduction under Alternative Crop Insurance and Disaster Assistance Designs, Western Journal of Agricultural Economics, 16(2): 238-250.

Chambers, R.G., 1989, Insurability and Moral Hazard in Agricultural Insurance Markets, American Journal of Agricultural Economics, 71: 604-616.

Chapuis D., 1994, Calamités Agricoles et Assurance Agricole, Risques 20: 33-43.

Gardner, B.L., 1994, Crop Insurance in U.S. Farm Policy, Economics of Agricultural Crop Insurance, in Theory and Evidence, Kliwer Academic Publishers: pp.17-44.

Gollier, C., 1996, Optimum Insurance of Approximate Losses, Journal of Risk and Insurance 63(3): 369-380.

Kamien, M.I. and N.L. Schwartz, 1981, Dynamic Optimization : the Calculus of Variations and Optimal Control in Economics and Management, North Holland.

Kihlstrom, R., D. Romer and S. Williams, 1981, Risk Aversion with Random lnitial Wealth, Econometrica 49: 911-920.

Knight, T.O. and H. Coble, 1997, Survey of U.S Multiple Peril Crop Insurance Literature since 1980, Review of Agriculiural Economics 19(1): 128-156.

Magnan, S., 1995, Catastrophe Insurance System in France, The Geneva Papers on Risk and Insurance 77: 474-780.

Mahul, O., 1997, A Note on Optimum Rainfall Insurance, discussion paper, INRA-ESR Rennes, France.

Meyer, J. and M. Ormiston, 1997, The Demand for Insurance when the Deductible Form of Indemnification is Optimal, FUR 8 Conference, July 2-5 1997, Mons, Belgium.

Miranda, M.J., 1991, Area-Yield Crop Insurance Reconsidered, American Journal of Agricultural Economics 73: 233-242.

Miranda, M.J. and J.W. Glauber, 1997, Systemic Risk, Reinsurance, and the Failure of Crop Insurance Markets, American Journal of Agricultural Economics 79: 206-215.

Nelson, C.H. and E.T. Loehman, 1987, Further toward a Theory of Agricultural Insurance, American Journal of Agriculiural Economics 69: 523-531.

Pratt, J.W. and R. Zeckhauser, 1987, Proper Risk Aversion, Econometrica 55: 143-154.

Quiggin, J., 1994, The Optimal Design of Crop Insurance, Economics of Agricultural Crop Insurance: Theory and Evidence, D.L. Hueth and W.H. Furtan, eds., pp.115134. Norrwell MA: Kluwer Academic Publishers.

Raviv, A., 1979, The Design of an Optimal Insurance Policy, American Economic Review 69: 84-96.

Skees, J.R. and M.R. Reed, 1986, Rate Making for Farm-Level Crop Insurance: Implications for Adverse Selection, American Journal of Agricultural Economics 78: 653-659.

Smith, V.H., H.H. Chouinard and A.E. Baquet, 1994, Almost Ideal Area Yield Crop Insurance Contracts, Agriculinural and Resource Economics Review 23: 75-83. 
